\title{
The Impact of Work-life Balance on Post-90s Young Employees on Innovative Behavior Empirical Research Based on Three Cities in Shandong Province
}

\author{
$\mathrm{Li} \mathrm{Wan}^{1, *}$ Jiakun Liu ${ }^{1}$
}

\author{
${ }^{1}$ School of Economics and Management, Shandong Youth University of Political Science, Jinan, Shandong 250103, \\ China \\ *Corresponding author. Email: 86974796@qq.com
}

\begin{abstract}
In the context of China's vigorous promotion of innovation and the construction of "Healthy China 2030", the research on work-life balance and innovative behavior is of great significance. This article takes 500 young post-90s employees in Jinan, Qingdao and Yantai of Shandong Province as research objects, and analyzes the relationship between work-life balance, sense of organizational support and innovative behavior. The results of empirical research have found that: the three factors of work-life balance, that is, work-family balance, work-vacation balance, work-growth balance and innovative behavior are significantly positively correlated; in the three factors of organizational support, work support plays a positive role in regulating work-family balance, work-growth balance and innovative behavior; recognition value plays a positive role in regulating work-growth balance and innovative behavior; caring for interests plays a positive role in regulating work-family balance and innovative behavior.
\end{abstract}

Keywords: post-90s young employees, work-life balance, sense of organizational support, innovative

behavior

\section{INTRODUCTION}

Post-90s young employees gradually entered the workplace. Against the social background of "421" family structure, they are under the dual pressure of work and life. Especially with the promulgation of the two-child policy, many families have changed from "421" to "422" structures, and they will shoulder the heavy responsibility of taking care of four elderly and two children. And with the development of the economy and the intensification of social competition, people's work and life rhythm is getting faster and faster, and the rest and entertainment time are severely squeezed. As a result, the post-90s young employees have role conflicts in the field of work and life. Huge role conflicts and excessive psychological burdens have caused the employees' physical health to deteriorate continuously. Work stress, death from overwork, and low happiness have become the key words of modern society. This casts a shadow on the development of China's economy and lays hidden dangers for the sustainable development of society and economy and the comprehensive realization of a healthy China.

In the new normal of economic development, innovation is the key to cracking down on corporate development problems and national economic transformation. The Fifth Plenary Session of the 18th CPC National Congress proposed: "To adhere to the development of innovation, it is a must to put innovation at the core of the country's overall development ", so as to form a new situation of "mass innovation" and "innovation of everyone", and make innovation prevail in the whole society. The post-90s young employees are an important force for national economic development and innovation. Whether they have innovative spirit and innovative behaviors plays an important role in the development and transformation of the national economy.

Are post-90s young employees' work-life balance related to innovative behavior? Is there an internal logical relationship between the two? Few scholars have conducted systematic analysis and empirical tests. Based on the above background, this article will explore the working mechanism and influence path between the post-90s young employees' work-life balance and innovative behavior, and introduce the sense of organizational support as a moderating variable to provide enterprises with management basis and reference, solve the problems of enterprise development, improve market competitiveness, 
promote the transition of national economic development and the comprehensive realization of healthy China.

\section{THEORETICAL BASIS AND RESEARCH ASSUMPTIONS}

\section{A. Definition of concepts}

1) Work-life balance: Work-life balance originates from the term "work-family conflict". In the late 1990s, scholars realized that non-work responsibilities and activities of employees can take many forms, not just family. As a result, scholars have begun to use the term "work-life balance" heavily.

Marks and Mac-Dermid (1996) [1] proposed the definition of work-life balance, that is, individuals and role partners play different roles together, and fully meet the needs of each role. Kirchmeyer (2000) [2] believes that work-life balance means that employees are in a satisfactory state in all areas of life, which is reflected in the ability to allocate time, energy, and personal resources. Jeffrey et al. (2003) [3] summarized the work-life balance into three aspects: time balance, that is, the amount of time devoted to work and life is equivalent; involvement balance, that is, the level of psychological commitment to work and life roles is equal; satisfaction balance means that life and work satisfaction are equal. This study draws on Jin Zhengyun and Piao Zhenglie's (2008) [4] definition of work-life balance, which is the three balanced aspects of work-life, work-vacation and work-growth perceived by employees.

2) Innovative behavior: Since Schumpeter first explicitly put forward the concept of "innovation", innovation has become an enduring topic in the field of economics and management, and subsequent research has focused on the field of psychology. Until the 1990s, American scholar Amabile introduced creativity research into organizational scenarios. Scott and Bruce (1994) [5] divided individual innovation behavior into three stages: (1) the establishment of a problem and the generation of a concept or solution; (2) seeking support for its concept; (3) by producing innovative standards or models, they can be spread, manufactured in large quantities, and then used in large quantities to complete their innovative ideas. After entering the 21st century, in the context of the country's vigorous promotion of independent innovation, Chinese scholars have begun to focus on individual-level innovation behaviors. Scholars have also recognized the importance of the innovation environment and have begun to shift their focus from simply focusing on technological innovation to creating an innovative environment and atmosphere. Li Zhi and Zhu Fan (2007) [6] believe that the current factors affecting employees' innovation ability mainly involve two aspects: one is the internal system factors of employees, including personality factors, skills factors, cognitive style factors, motivation factors, and value factors; the other is the external system factors of employees, mainly including organizational climate factors, corporate manager factors and management mode factors. This study draws on Gu Yuandong and Peng Jisheng's (2010) [7] definition of innovative behavior, that is, the behavior of individuals introducing new ideas into work and giving them to practice.

3) Sense of organizational support: The concept of organizational support was first proposed by Professor Eisenberger in the American Journal of Applied Psychology in 1986. The sense of organizational support is the overall feeling of an organization's employees about how much the organization values their contributions and their welfare, that is, the sense of organizational support is a kind of perception that the employees exchange their hard work and loyalty to the organization for the reward and attention of the organization. This concept has two core points: one is the employee's feelings about whether the organization values his contribution; the other is the employee's feelings about whether the organization pays attention to their happiness [8]. Since then, scholars have proposed various concepts of organizational support based on different research perspectives and concerns. Chinese scholars have also carried out a certain amount of research based on the Chinese cultural background. Ling Wenquan et al. (2006) [9] considered that organizational support is employees' views on how the organization views their contributions and care for their interests. They also revised the organizational support measurement scale to divide organizational support into two dimensions of work support and life support perceived by employees. In terms of the influencing factors of organizational factors, they mainly include organizational factors such as working conditions, organizational fairness and superior support, and individual factors such as individual characteristics variables and demographic characteristics of employees. While the sense of organizational support has a significant impact on employee attitudes and role behaviors [10].

B. The relationship between work-life balance, organizational support and employee innovation

1) Relationship between work-life balance and innovative behavior: In terms of work-life balance and employee innovation behavior research, Amabile \& Gryskiewicz (1987) [11] proposed that according to 
scientific investigations, $33 \%$ of innovation behaviors need sufficient time guarantee. The sense of time pressure has a significant negative correlation with the employee's innovative behavior, that is, the stronger the employee's sense of time pressure, the less innovative behavior is generated. Compared with time pressure, employees with more time have more innovative points and ideas in their work. If employees have a high degree of work-life balance, they will be relatively relaxed physically and mentally, and they will be creative at work and promote innovative thinking and behaviors at work. In Lee Kang-Su's (2014) [12] research on the impact of family-friendly systems on employee organizational commitment and innovative behavior, the results show that employees' work-life balance has a significant positive impact on innovative behavior. Based on the above research results, the following theoretical assumptions are proposed:

Hypothesis 1: Work-life balance has a significant positive impact on employee's innovative behavior

Hypothesis 1-1: Work-family balance has a significant positive impact on employee's innovative behavior

Hypothesis 1-2: Work-vacation balance has a significant positive impact on employee's innovative behavior

Hypothesis 1-3: Work-growth balance has a significant positive impact on employee's innovative behavior

2) The relationship between work-life balance, sense of organizational support and innovative behavior: In recent years, more and more companies and organizations have introduced work-life balance plans and strategies into employee management, providing various support from an organizational perspective to help employees. From the concept definition and literature review, it can be seen that organizational support is the organizational support felt by employees, and has a significant impact on employees' attitudes and behaviors. The impact of employee work-life balance on innovative behavior may change due to the perceived organizational support of individuals. According to the social exchange theory, when employees feel the support and care from the organization, they will be motivated to exchange due to the incentive effect, which will be further reflected in their work attitude and behavior. This will lead to more positive behaviors of employees, such as actively seeking changes that can benefit the organization; when problems are found in the organization or at work, employees will actively seek new ways to solve problems, which is conducive to the creation of innovative behaviors. $\mathrm{Xu}$ Yan and Zhao Shuming (2011) [13] also proposed that the creation of member innovation is directly affected by the employment and security policies of the organization, and that work and emotional support indirectly have a positive effect on it. Therefore, on the basis of exploring work-life balance on innovative behavior, this study further explores the moderating effect of organizational support on worklife balance and innovative behavior [14]. Lu Jihua et al. [15] found that organizational support meets the psychological needs of employees. When employees feel that the organization is willing and able to support their work and bring corresponding rewards, they will consciously invest in the behavior expected by the organization, make more efforts for the benefit of the organization, and even make various innovative attempts with risky nature.

Based on the above research, the following hypotheses are proposed:

Hypothesis 2: Organizational support plays a moderating role between work-life balance and innovative behavior

Hypothesis 2-1: Organizational support plays a moderating role between work-family balance and innovative behavior

Hypothesis 2-1-1: Work support plays a moderating role between work-family balance and innovative behavior

Hypothesis 2-1-2: Recognition value plays a moderating role between work-family balance and innovative behavior

Hypothesis 2-1-3: Caring for interests plays a moderating role between work-family balance and innovative behavior

Hypothesis 2-2: Organizational support plays a moderating role between work-leave balance and innovative behavior

Hypothesis 2-2-1: Work support plays a moderating role between work-leave balance and innovative behavior

Hypothesis 2-2-2: Identity value plays a moderating role between work-vacation balance and innovative behavior

Hypothesis 2-2-3: Caring for interests plays a moderating role between work-vacation balance and innovative behavior

Hypothesis 2-3: Organizational support plays a moderating role between work-growth balance and innovative behavior 
Hypothesis 2-3-1: Work support plays a moderating role between work-growth balance and innovative behavior

Hypothesis 2-3-2: Identity value plays a moderating role between work-growth balance and innovative behavior

Hypothesis 2-3-3: Caring for interests plays a moderating role between work-growth balance and innovative behavior

\section{RESEARCH METHODS}

\section{A. Sample and data collection}

This paper uses statistical surveys to explore the inherent relationships between work-life balance, social support and innovative behavior. This study was conducted from August to December 2019 in a completely anonymous form. A total of 500 questionnaires were distributed to 500 post-90s young employees in Jinan, Qingdao and Yantai, Shandong Province.467 copies were recovered and the questionnaire recovery rate was $93.4 \%$. After all the questionnaires were collected, the waste paper was processed, and 428 valid questionnaires were obtained, and the effective rate was $91.6 \%$. In terms of gender, 240 subjects were male, accounting for $56.1 \%$, and women were 188 , accounting for $43.9 \%$; in terms of age, 16 subjects were under 21 , accounting for $3.7 \%$, and 187 subjects were between 22 to 24 , accounting for $43.7 . \%, 215$ subjects were between 25 to 27 , accounting for $51.5 \%$; in terms of marriage, 320 subjects were unmarried employees, accounting for $74.8 \%$, and 108 subjects were married employees, accounting for $25.2 \%$; in terms of academic qualifications, 30 were from high schools and technical secondary schools (and below), accounting for $7 \%$; 80 were from junior colleges, accounting for $18.7 \%$; 249 were from undergraduates, accounting for $58.2 \%$, and 69 were from graduates and above, accounting for $16.1 \%$.

\section{B. Variable measurement}

1) Work-life balance: The work-life balance scale uses a questionnaire developed by Jin Zhengyun and Piao Zhenglie (2008). This questionnaire has been used many times by Korean scholars, and its reliability and validity have been supported. This questionnaire contains 25 questions, which are divided into three factors: work-life, work-vacation and work-growth balance. Using Likert's 5-point scale, the answers to specific questions are: strongly disagree, not very much agree, neutral, relatively agree and strongly agree five levels; 1 means strongly disagree and 5 means strongly agree.
2) Sense of organizational support: The sense of organizational support adopts a scale developed by Chinese scholars Ling Wenshuan and Yang Haijun (2006) based on the background of the Chinese context. This questionnaire consists of 24 items and consists of three factors: job support, recognition of value, and caring for interests. The scale has a high internal consistency coefficient and good stability, and has been widely used in China's local context for organizational support and related research. Using Likert's 5-point scale, the answers to specific questions are: strongly disagree, not very much agree, neutral, relatively agree and strongly agree five levels; 1 means strongly disagree and 5 means strongly agree.

3) Innovative behavior: In this study, the scale revised by Zhang Tingting (2009) was used. The original scale was the innovative behavior scale revised by Wu Jingji (2006). Combining some of the items in the research of Scott \& Bruce (1994), Janssen (2000) and Choi (2004), according to the research needs, the "Employee Innovative Behavior Scale" has been formed. The scale has 1 dimension and includes 6 items. Using Likert's 5-point scale, the answers to specific questions are: strongly disagree, not very much agree, neutral, relatively agree and strongly agree five levels; 1 means strongly disagree and 5 means strongly agree. The research model is as "Fig. 1": 


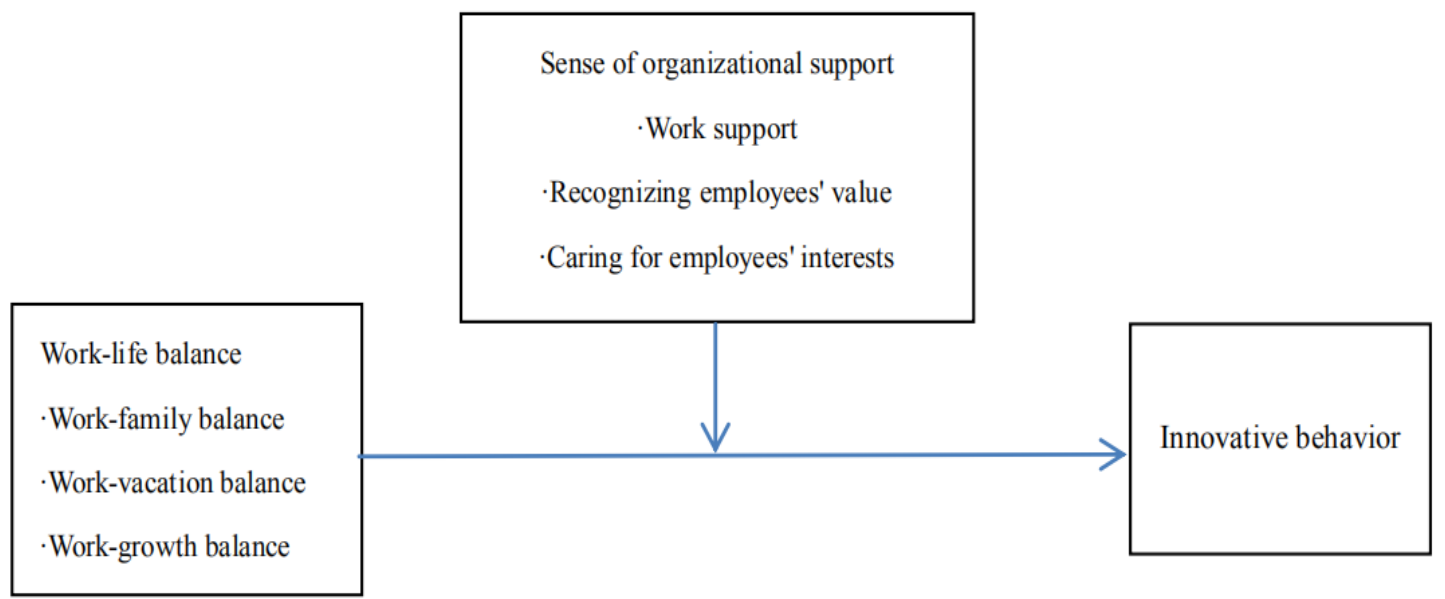

Fig. 1. Research model of this paper.

\section{EMPIRICAL ANALYSIS AND HYPOTHESIS VERIFICATION}

\section{A. Reliability and validity test}

1) Reliability and validity of the work-life balance scale: In order to confirm whether the work-life balance measurement project is suitable for factor analysis, the KMO and Bartlett tests were first performed on the scale. The KMO value of the work-life balance was 0.933, and the significance coefficient of the Bartlett test was 0.000 , indicating that the data correlation matrix is not the identity matrix, and the data is also suitable for factor analysis. Based on this, a factor analysis of work-life balance was conducted, and it was found that there are three common factors with characteristic roots greater than 1 , which can explain $70.690 \%$ of the total variance, and the factor load is between 0.587-0.790. According to the literature review and project title, these three factors are named workfamily balance, work-vacation balance and workgrowth balance. The a-factor of the three factors is between 0.797-0.985, which indicates that the scale has good validity.

2) Reliability and validity of organizational support: The KMO value of the sense of organizational support is 0.931, and the significance coefficient of the Bartlett test is 0.000 , indicating that the data correlation matrix is not an identity matrix, and the data is also suitable for factor analysis. Based on this, a factor analysis was performed on the sense of organizational support. It was found that there are three common factors with characteristic roots greater than 1 , which can explain $78.244 \%$ of the total variance, and the factor load is between 0.708 and 0.904 . According to the literature review and project title, the three factors were named work support, recognition of work value, and caring for interests. The a-factor of the three factors is between 0.852-0.985, which indicates that the scale has good validity.

3) Reliability and validity of the innovative behavior scale: The KMO value of the innovative behavior is 0.698 , and the significance coefficient of the Bartlett test is 0.000 , which indicates that the data correlation matrix is not an identity matrix and is also suitable for factor analysis. Based on this, a factor analysis of the innovative behavior was carried out, and it was found that there was a common factor with a characteristic root greater than 1 , which can explain 58.085 of the total variance, and the factor load was between 0.636 and 0.938 . According to the literature review and project title, this factor is named innovative behavior. The factor a factor is .797 , which indicates good scale validity.

\section{B. Hypothesis test results}

1) Hypothesis test based on correlation analysis: On the basis of ensuring the reliability of the scale, before performing structural equation model tests on each hypothetical model, a correlation analysis was performed between the variables. The analysis results are shown in "Table I". All correlation coefficients were significantly correlated at the 0.001 level.

As can be seen from "Table I" below, three variables of independent work-life balance: workfamily balance, work-vacation balance, work-growth balance, and the three variables that regulate the sense of organizational support: work support, recognition of value, caring for benefits and the correlation coefficient of dependent variable innovation behavior all reached a significant level. The previous hypotheses have been initially verified. Through correlation analysis, the correlations and correlation coefficients between the 
variables were found, but the causal relationship between the variables has not been found, so the next step of regression analysis is needed to verify the causal relationship between the variables. Moreover, there were significant correlations between gender, age, marriage, degree, and each variable.

TABLE I. CORRELATION ANALYSIS OF VARIABLES

\begin{tabular}{|c|c|c|c|c|c|c|c|c|c|c|}
\hline & 1 & 2 & 3 & 4 & 5 & 6 & 7 & 8 & 9 & 10 \\
\hline 1 Gender & 1 & & & & & & & & & \\
\hline 2 Age & $\begin{array}{l}134 \\
* *\end{array}$ & 1 & & & & & & & & \\
\hline 3 Married or not & 059 & $\begin{array}{l}006 \\
* *\end{array}$ & 1 & & & & & & & \\
\hline 4 Work-family balance & $\begin{array}{l}206 \\
* *\end{array}$ & $\begin{array}{l}325 \\
* *\end{array}$ & $\begin{array}{l}061 \\
* *\end{array}$ & 1 & & & & & & \\
\hline 5 Work-vacation balance & $\begin{array}{l}255 \\
* *\end{array}$ & $\begin{array}{l}381 \\
* *\end{array}$ & $\begin{array}{l}097 \\
* *\end{array}$ & $\begin{array}{l}766 \\
* *\end{array}$ & $\begin{array}{l}1 \\
* *\end{array}$ & & & & & \\
\hline 6 Work-growth balance & $\begin{array}{l}168 \\
* *\end{array}$ & $\begin{array}{l}293 \\
* *\end{array}$ & $\begin{array}{l}035 \\
* *\end{array}$ & $\begin{array}{l}702 \\
* *\end{array}$ & $\begin{array}{l}737 \\
* *\end{array}$ & $\begin{array}{l}1 \\
* *\end{array}$ & & & & \\
\hline 7 Work support & $\begin{array}{l}180 \\
* *\end{array}$ & $\begin{array}{l}291 \\
* *\end{array}$ & $\begin{array}{l}094 \\
* *\end{array}$ & $\begin{array}{l}560 \\
* *\end{array}$ & $\begin{array}{l}603 \\
* *\end{array}$ & $\begin{array}{l}589 \\
* *\end{array}$ & 1 & & & \\
\hline 8 Identity value & $\begin{array}{l}232 \\
* *\end{array}$ & $\begin{array}{l}314 \\
* *\end{array}$ & $\begin{array}{l}150 \\
* *\end{array}$ & $\begin{array}{l}605 \\
* *\end{array}$ & $\begin{array}{l}675 \\
* *\end{array}$ & $\begin{array}{l}595 \\
* *\end{array}$ & $\begin{array}{l}632 \\
* *\end{array}$ & 1 & & \\
\hline 9 Caring for interests & $\begin{array}{l}155 \\
* *\end{array}$ & $\begin{array}{l}275 \\
275\end{array}$ & $\begin{array}{l}114 \\
* *\end{array}$ & $\begin{array}{l}427 \\
* *\end{array}$ & $\begin{array}{l}506 \\
* *\end{array}$ & $\begin{array}{l}479 \\
* *\end{array}$ & $\begin{array}{l}671 \\
* *\end{array}$ & $\begin{array}{l}491 \\
* *\end{array}$ & 1 & \\
\hline 10 Innovative behavior & $\begin{array}{l}155 \\
* *\end{array}$ & $\begin{array}{l}333 \\
* *\end{array}$ & $\begin{array}{l}319 \\
* *\end{array}$ & $\begin{array}{l}563 \\
* *\end{array}$ & $\begin{array}{l}590 \\
* *\end{array}$ & $\begin{array}{l}502 \\
* *\end{array}$ & $\begin{array}{l}489 \\
* *\end{array}$ & $\begin{array}{l}526 \\
* *\end{array}$ & $\begin{array}{l}496 \\
* *\end{array}$ & 1 \\
\hline
\end{tabular}

2) Hypothesis test based on regression analysis: In order to further clarify the relationship between the variables, this paper takes the influence of control variables such as gender, age, marital status, and educational background into consideration, and uses hierarchical multiple regression to analyze the main variables. The data were normalized and multicollinearity testing was performed before regression. No obvious collinearity problem was found between the predictors, indicating that the results of the regression analysis were reliable.

The first step is to add control variables such as gender, age, marital status, and education to Model 1, which is established $\left(\mathrm{R}^{2}=0.229\right)$, showing that control variables such as gender, age, marital status, and education can explain $22.9 \%$ of the variation in innovative behavior. Among them, gender (-.095*) and marital status $(-.317 * *)$ are negatively related to innovative behavior; age $(.322 * *)$ and education $\left(.083^{*}\right)$ are positively related to innovative behavior. The second step is to add the main effect of work-life balance (Model 2). As can be seen from "Table II", the $F$ value is 51.350 and the $R^{2}$ value is 0.461 , which can explain $46.1 \%$ of the individual employee's innovative behavior variation, has $23.2 \%$ more explanatory power than Model 1. The three factors that indicate work-life balance: work-family balance, work-vacation balance, and work-growth balance have a significant positive correlation with innovative behavior. Model 2 is established. Hypotheses 1-1, 1-2 and 1-3 are verified.
The third step is to add organizational support (Model 3), recognition value (Model 4), and caring for interests (Model 5) in turn. The F values respectively are 46.946, 46.013, 49.469, and the $\mathrm{R}^{2}$ values respectively are $0.473,468$, and 486 , which can explain $47.3 \%, 46.8 \%$, and $48.6 \%$ of the individual employee's innovative behavior variation, increasing the explanatory power by $1.2 \%, 0.7 \%$, and $2.5 \%$ respectively compared with Model 2; work support $\left(.141^{* *}\right)$ is positively related to innovative behavior.

The fourth step is to add work-life balance and work support interaction items (Model 6), work-life balance and recognition value interaction items (Model 7), and work-life balance and caring for interests interaction items (Model 8). The F value is 36.342, 33.981, 36.763 respectively, and the $\mathrm{R}^{2}$ value is $.490, .473$, and .493 respectively, which can explain $49.0 \%, 47.3 \%$, and $49.3 \%$ of the individual innovative behavior variation of employees respectively, increasing the explanatory power by $1.7 \%, 0.5 \%$ and $0.7 \%$ respectively compared with Model 3, 4 and 5. Among them, the interaction term coefficients of work-family balance, work-growth balance and work support are $1.700 * *$ and $.1 .296^{* *}$, the interaction term coefficient of work-growth balance and recognition value is $.977^{*}$ and the interaction term coefficient for work-family balance and caring for interest is $1.078^{*}$. This shows that organizational support has a significant role in regulating the relationship between work-family balance, workgrowth balance, and innovative behavior. Recognition 
value has a significant moderating effect on the relationship between work-growth balance and innovative behavior, and caring for interests has a significant moderating effect on the relationship between work-family balance and innovative behavior. Hypotheses 2-1-1, 2-1-3, 2-3-1 and 2-3-2 have been verified. Other hypotheses have not been verified.("Table II")

TABLE II. ORGANIZATIONAL SUPPORT MODERATION TEST OF WORK-LIFE BALANCE AND INNOVATIVE BEHAVIOR

\begin{tabular}{|c|c|c|c|c|c|c|c|c|}
\hline & \multicolumn{8}{|c|}{ Innovative behavior } \\
\hline & Model 1 & Model 2 & Model 3 & Model 4 & Model 5 & Model 6 & Model 7 & Model 8 \\
\hline Gender & $.095^{*}$ & .009 & .013 & .016 & .013 & .022 & .020 & .021 \\
\hline Age & $.322 * *$ & $.133 * *$ & $.124 * *$ & $.126 * *$ & $.117 * *$ & $.116^{* *}$ & $.120^{* * *}$ & $.116^{* *}$ \\
\hline Married or not & $.317 * *$ & $.278 * *$ & $.271^{* *}$ & $.266^{* *}$ & $.263 * *$ & $.272 * *$ & $.255^{* *}$ & $.265^{* *}$ \\
\hline Education background & $.083^{*}$ & .026 & .029 & .019 & .036 & .032 & .011 & .031 \\
\hline Work-family balance & & $.194 * *$ & $.173 * *$ & $.155^{* *}$ & $.129 *$ & $.907 * *$ & .156 & $.465^{*}$ \\
\hline Work-vacation balance & & $.284 * *$ & $.248 * *$ & $.251 * *$ & $.263 * *$ & .263 & .001 & $.574 *$ \\
\hline Work-growth balance & & $.108 *$ & .069 & $.093 *$ & .082 & $.829 * *$ & $.627^{*}$ & .364 \\
\hline Work support & & & $.141 * *$ & & & .105 & & \\
\hline Recognition value & & & & $.119 *$ & & & .156 & \\
\hline Caring for interests & & & & & $.193 * *$ & & & .367 \\
\hline $\begin{array}{l}\text { Work-family balance } \times \\
\text { Work support }\end{array}$ & & & & & & $1.700 * *$ & & \\
\hline $\begin{array}{c}\text { Work-vacation balance } \times \\
\text { Work support }\end{array}$ & & & & & & .099 & & \\
\hline $\begin{array}{l}\text { Work-growth balance } \times \\
\text { Work support }\end{array}$ & & & & & & $1.296^{* *}$ & & \\
\hline $\begin{array}{l}\text { Work-family balance } \times \\
\text { Recognition value }\end{array}$ & & & & & & & .477 & \\
\hline $\begin{array}{c}\text { Work-vacation balance } \times \\
\text { Recognition value }\end{array}$ & & & & & & & .523 & \\
\hline $\begin{array}{c}\text { Work-growth balance } \times \\
\text { Recognition value }\end{array}$ & & & & & & & $.977 *$ & \\
\hline $\begin{array}{l}\text { Work-family balance } \times \\
\text { Caring for interests }\end{array}$ & & & & & & & & $1.078^{*}$ \\
\hline $\begin{array}{l}\text { Work-vacation balance } \times \\
\text { Caring for interests }\end{array}$ & & & & & & & & .647 \\
\hline $\begin{array}{c}\text { Work-growth balance } \times \\
\text { Caring for interests }\end{array}$ & & & & & & & & .560 \\
\hline Adjusted $R^{2}$ & .222 & .452 & .463 & .458 & .476 & .477 & .459 & .480 \\
\hline$R^{2}$ & .229 & .461 & .473 & .468 & .486 & .490 & .473 & .493 \\
\hline$\triangle R^{2}$ & & 0.232 & 0.012 & 0.007 & 0.015 & 0.017 & 0.005 & 0.007 \\
\hline$F$ & 31.409 & 51.350 & 46.9456 & 46.013 & 49.469 & 36.342 & 33.981 & 36.763 \\
\hline
\end{tabular}

In order to show the regulatory effects more clearly, this paper refers to the methods provided by Aiken and West, and tests the regression coefficients of the high and low score groups of the moderator (sense of organizational support) respectively. The moderation effect diagram is shown in "Fig. 2", "Fig. 3", "Fig. 4" and "Fig. 5". The slope of the high score group is significantly higher than that of the low score group and 
the slope is positive, indicating that work support enhances the positive relationship between work-family balance, work growth balance and innovative behavior; recognition value enhances the positive relationship between work-growth balance and innovative behavior; caring for benefits enhances the positive relationship between work-family balance and innovative behavior, further verifying hypotheses 2-1-1, 2-1-2 3, 2-3-1 and 2-3-2.

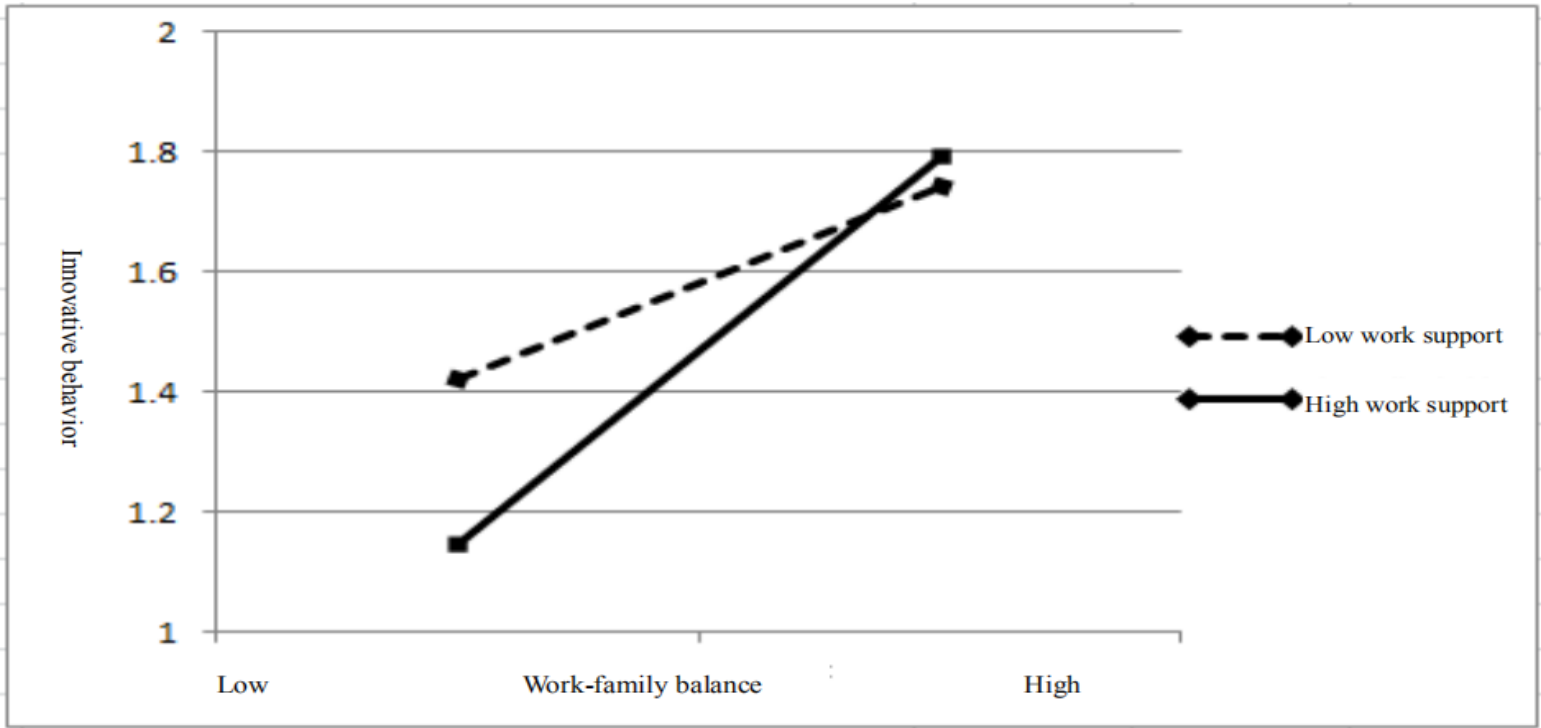

Fig. 2. Moderation effect diagram of work support.

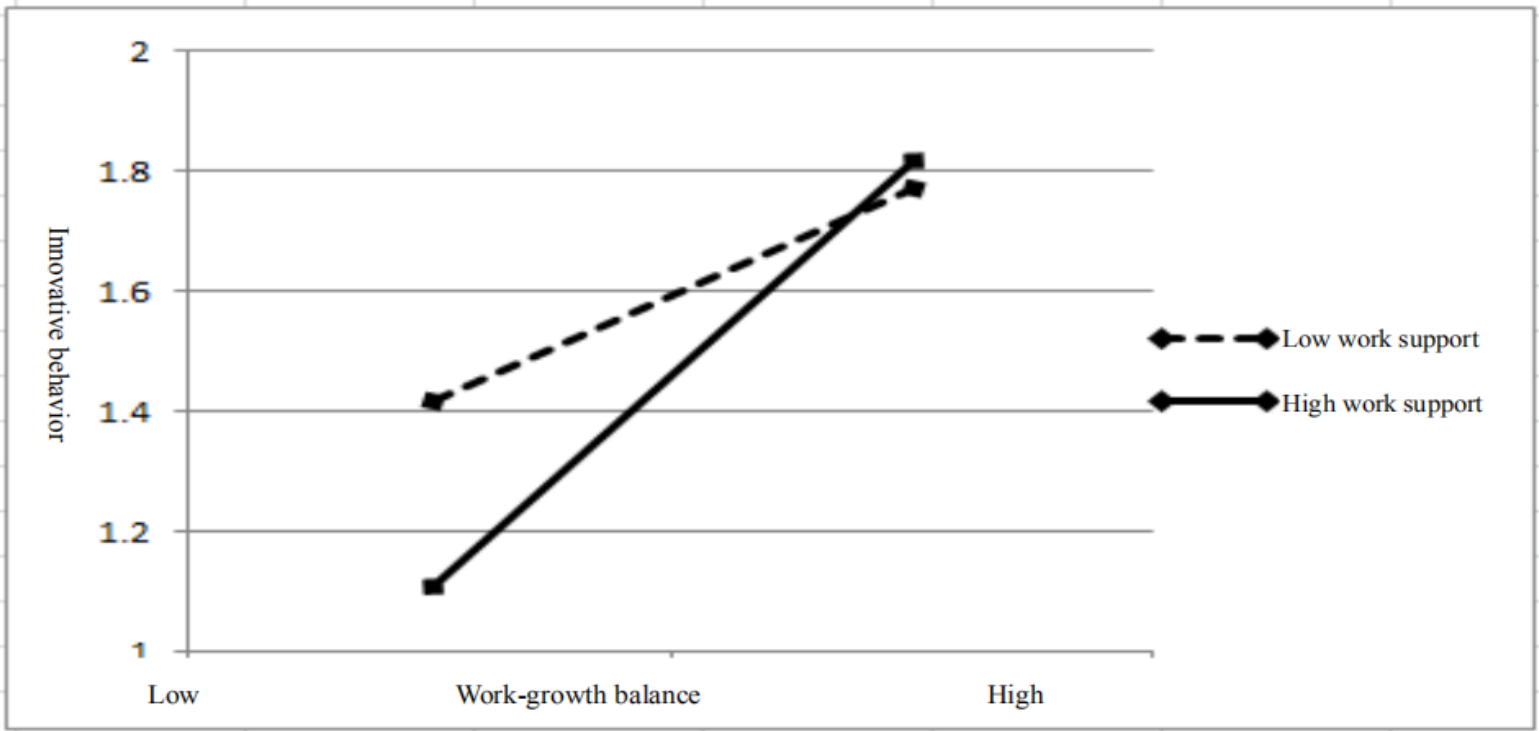

Fig. 3. Moderation effect diagram of work support. 


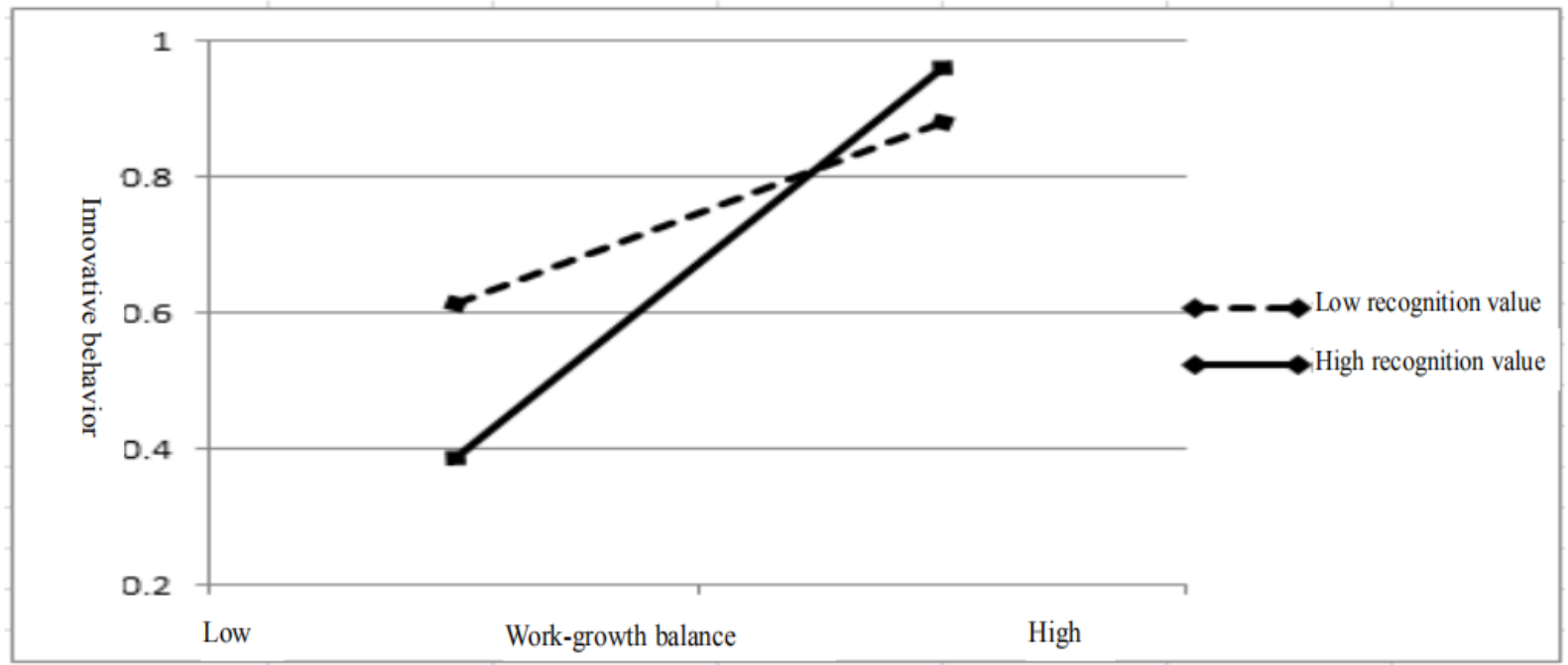

Fig. 4. Moderation effect diagram of recognition value .

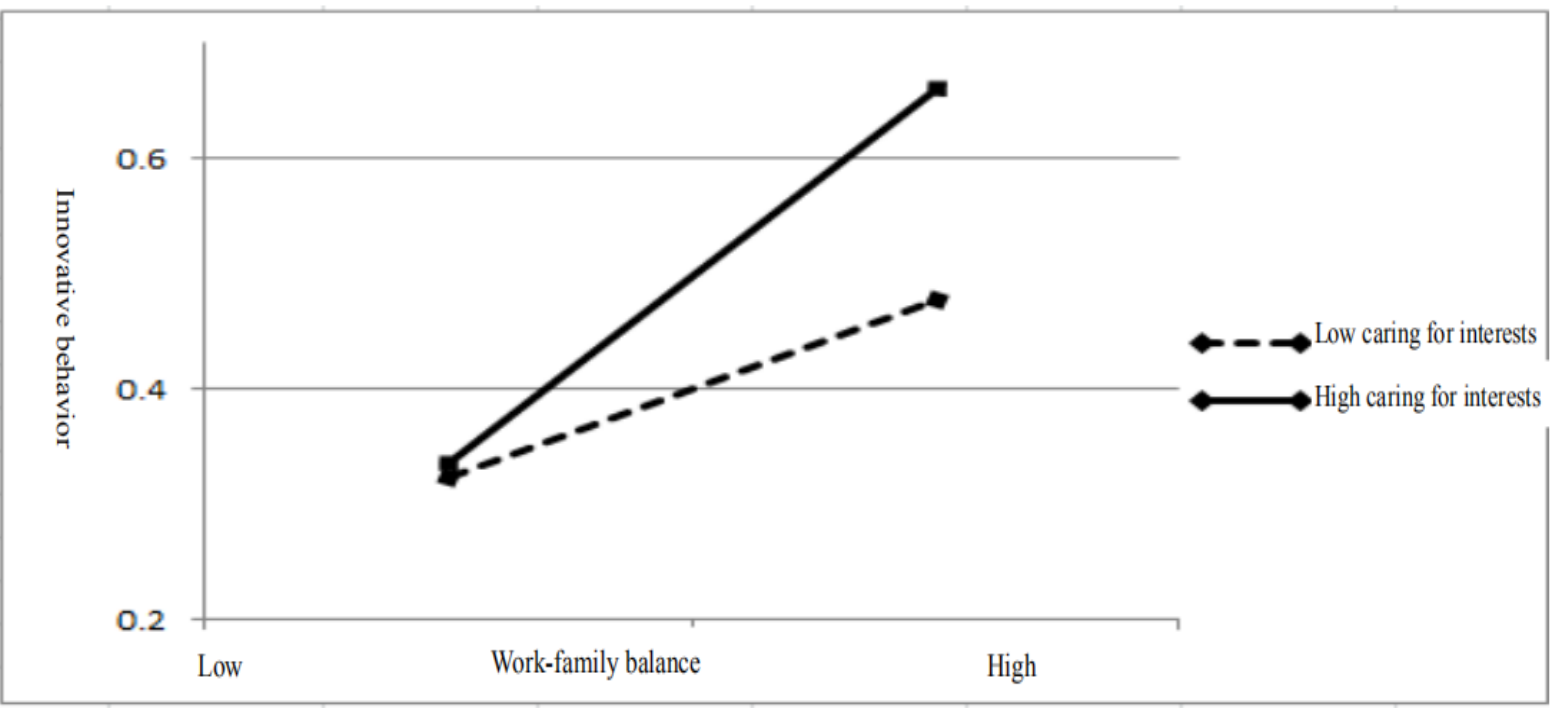

Fig. 5. Moderation effect diagram of caring for interests.

\section{CONCLUSIONS AND IMPLICATIONS}

\section{A. Conclusion and discussion}

Based on the perspective of post-90s young employees, this study empirically analyzes the relationship between work-life balance, organizational support and innovative behavior. The research conclusions are as follows:

First, the relationship between work-life balance and innovative behavior is as follows. The three factors of work-life balance: work-family balance, workvacation balance and work-growth balance all have significant positive correlations with innovative behavior, indicating that the higher the work-life balance of post-90s young employees, the more innovative behaviors they can promote in the work process.

Second, the role of organizational support in mediating work-life balance and innovative behavior is as follows. Factors of organizational support: work support plays a positive role in regulating work-family balance, work-growth balance, and innovative behavior. Factors of organizational support: recognition value plays a positive regulating role between work-growth balance and innovative behavior. Factors of organizational support: caring for interests plays a positive regulating role between work-family balance and innovative behavior. 
At the same time, in the factors of organizational support, the moderating effect of work support between work-vacation and behavior, recognition value between work-family balance and work-vacation balance and innovative behavior, and caring for interests in workvacation balance and work growth and innovative behavior has not been verified. Through in-depth interviews with 30 post-90s young employees in Jinan, the following explanations can be drawn. On the one hand, in terms of the three areas of family, growth and vacation, employees hope to get more support from the organizational level in family and growth. Especially for young employees in the post-90s period, they pay more attention to personal development and growth. On the other hand, in terms of work and vacations, employees in China are basically on vacation in accordance with national statutory holidays. In reality, it is difficult to obtain vacation support from the organization, resulting in employees' less sensitive to the vacation support given by the organizational level and more sensitive to family and growth support given by the organizational level.

\section{B. Implications}

Based on the working mechanisms of work-life balance, organizational support, and innovative behavior of the post-90s young employees, the following enlightenment can be provided for relevant companies.

First of all, companies can improve the work-life balance of employees by formulating relevant corporate systems. Companies can implement flexible work systems and work week reduction systems that are conducive to work-life balance, improve the ability of employees to adapt to the requirements of work and life and improve employees' life quality and reduce their worries.

Secondly, companies can formulate corresponding management strategies to improve employees' sense of organizational support. Organizations can help employees in multiple ways, such as conducting lectures or consulting services on how to balance work and life, setting up professional departments or entrusting public institutions, providing information of nursing centers and other organizational support.

\section{Research limitations and prospects}

First of all, this study draws on some of the more mature scales of foreign scholars. Due to differences in ideology, culture, and systems, there may be some differences from the Chinese scenario.

Secondly, this research is mainly based on the perspective of post-90s young employees to explore the relationship between work-life balance, organizational support and innovative behavior. The specificity of the research object may affect the universality of the research results. In future research, the number and scope of samples need to be expanded to further verify the relationship between the three.

\section{References}

[1] Marks S R, Mac Dermid S M. Multiple roles and the self: A theory of rolebalance [J]. Journal of Marriage and the Family, 1996: 417-432.

[2] Kirchmeyer C. Work-life initiatives: greed or benevolence regarding workers' time? [J]. Trends in organizati -onal behavior, 2000,7: 79-94.

[3] E. Jeffrey Hill, Maria Ferris, Vjollca. Does it Matter Where You Work? A Comparison of How Three Work Venues (Traditional Office, Virtual Office, and Home Office) Influence Aspects of Work and Personal/ Family Life [J]. Journal of Vocational Behavior, 2003,(63).

[4] Kim Jeong-un, Park Jung Yeol. A Study for Work-Life Balance scale development [J]. Leisure studies,2008(3): 53-69.

[5] Scott S G, Bruce RA. Determinants of innovativebehavior: A path model of individual innovation in thework place [J] Academy of Management Journal,1994,37 :580 607.

[6] Li Zhi, Zhu Fan. Research progress on the innovation ability of employees in foreign companies and related enlightenment Journal of Southwest Jiaotong University (Social Science), 2007, 2: 114 -117. (in Chinese)

[7] Gu Yuandong, Peng Jisheng. The Impact of Organizational Innovation Climate on Employees' Innovative Behavior: The Mediating Role of Innovation Self-Efficacy [J]. Nankai Management Review, 2010, No. 1, 30-41. (in Chinese)

[8] Xu Xiaofeng, Che Hongsheng, Lin Xuanhui. The theory and research of organizational support [J]. Psychological Science, 2005, 28 (1): 130-132. (in Chinese)

[9] Ling Wenquan, Yang Haijun, Fang Liluo. Organizational Employees' Sense of Organizational Support [J]. Acta Psychologica Sinica, 2006, (2): 281-287. (in Chinese)

[10] Zhou Fei, Jia Bo. A Review of Researches on Organizational Support [J]. Journal of Liaoning University (Philosophy and Social Science Edition), 2014, (2): 105-109. (in Chinese)

[11] Amabile T M.\& Gryskiewicz S S. Creativity in the R\&D laboratory. Technical Report No. 30, Ce- nter for Creative Leadership, Greensboro, NC, 1987.

[12] Lee Kang-su. The effects of Family-Friendly In stitutions on Employ-ee's Organizational Commitment and Innovative Behavio [D]. Chonbu, Chonbuk National University, 2014.

[13] Xu Yan, Zhao Shuming. Research on the dual path model of employment security and employee innovative behaviors [J]. Scientific Progress and Countermeasures, 2011, 28 (21): 136139. (in Chinese)

[14] Sun Jianmin, Jiao Haitao, Zhao Jian. Moderating effect of sense of organizational support on the relationship between work engagement and work-family conflicts [J]. Applied Psychology, 2011, 17 (1): 31-35. (in Chinese)

[15] Lu Jihua, Chen Lili, Zhao Xinan. Research on the Relationship between Organizational Support, Organizational Commitment and Professional Employees' Dedication [J]. Science of Science and Technology Management, 2013 (1): 147-153. (in Chinese) 